\title{
Cytokine \& chemokine response in the lungs, pleural fluid and serum in thoracic surgery using one-lung ventilation
}

\author{
Andreas Breunig ${ }^{1}$, Franco Gambazzi ${ }^{2}$, Beatrice Beck-Schimmer ${ }^{3}$, Michael Tamm ${ }^{4}$, Didier Lardinois ${ }^{2}$, Daniel Oertli ${ }^{1}$ \\ and Urs Zingg ${ }^{1 *}$
}

\begin{abstract}
Background: Thoracic surgery mandates usually a one-lung ventilation (OLV) strategy with the collapse of the operated lung and ventilation of the non-operated lung. These procedures trigger a substantial inflammatory response. The aim of this study was to analyze the cytokine and chemokine reaction in both lungs, pleural space and blood in patients undergoing lung resection with OLV with special interest in the chemokine growthregulated peptide alpha (GRO $\alpha$ ) which is the human equivalent to the rat cytokine-induced neutrophil chemoattractant-1 (CINC-1).
\end{abstract}

Methods: Broncho-alveolar lavage (BAL) fluid of both the collapsed, operated and the ventilated, non-operated lung, respectively, pleural space drainage fluid and blood was collected and the concentrations of interleukin (IL)-6, IL-1RA and GRO $\alpha$ were determined with enzyme-linked immunosorbent assays in 15 patients.

Results: Substantial inter-individual differences in the BAL fluid between patients in cytokine and chemokine levels occurred. In the pleural fluid and the blood these inter-individual differences were less pronounced. Both sides of the lung were affected and showed a significant increase in IL- 6 and IL-1RA concentrations over time but not in GRO $\alpha$ concentrations. Except for IL-6, which increased more in the collapsed, operated lung, no difference between the collapsed, operated and the ventilated, non-operated lung occurred. In the blood, IL-6 and IL-1RA increased early, already at the end of surgery. GRO $\alpha$ was not detectable. In the pleural fluid, both cytokine and chemokine concentrations increased by day one. The increase was significantly higher in the pleural fluid compared to the blood.

Conclusion: The inflammatory response of cytokines affects both the collapsed, operated and the ventilated, nonoperated lungs. The difference in extent of response underlines the complexity of the inflammatory processes during OLV. In contrast to the cytokines, the chemokine GRO $\alpha$ concentrations did not react in the BAL fluid or in the blood. This indicates that GRO $\alpha$ might not be useful as marker for the inflammatory reaction in complex surgical procedures.

Keywords: Inflammation, cytokines, chemokines, thoracic surgery, one-lung ventilation

\section{Background}

Thoracic surgery such as esophagectomy or lobectomy triggers a more severe systemic inflammatory reaction than intra-abdominal surgery [1]. One possible explanation is the fact that most thoracic procedures mandate a one-lung ventilation (OLV) strategy. The OLV leads to a collapse of the lung that is operated with subsequent shunting of blood and possible hypoxemia. The contralateral lung is

\footnotetext{
* Correspondence: uzingg@me.com

'Department of Surgery, University Hospital Basel, Switzerland

Full list of author information is available at the end of the article
}

ventilated and may suffer from ventilator-induced injury, hyperoxia and increased capillary stress [2-4].

A number of studies investigated cytokine levels in thoracic surgery [5-9]. The degree of inflammatory response depended on the extent of the surgical trauma (thoracotomy vs. video-assisted thoracic surgery) and the nature of the disease (benign vs. malign) [5-7]. Cytokine levels, especially interleukin-6 (IL-6) and interleukin-8 (IL-8), were associated with postoperative infections and systemic inflammatory response syndrome, which itself was a predictive factor the duration of the hospital stay $[8,9]$.
C Biomed Central

C 2011 Breunig et al; licensee BioMed Central Ltd. This is an Open Access article distributed under the terms of the Creative Commons Attribution License (http://creativecommons.org/licenses/by/2.0), which permits unrestricted use, distribution, and reproduction in any medium, provided the original work is properly cited. 
The influence of the OLV on the inflammatory process is still unclear. Most studies addressing cytokine production in thoracic surgery measured serum cytokine levels. Measurements in other compartments such as the pleural space and the collapsed and ventilated lungs by bronchoalveolar lavage (BAL) are scarce. Cree et al. demonstrated higher IL-8 levels in the BAL fluid after esophagectomy compared to the peripheral blood [10]. These authors also analyzed BAL samples from both lungs without showing a difference. However, the authors compared right and left lungs of two different groups of patients. Our group demonstrated a more pronounced inflammatory response on the ventilated left lung in patients undergoing transthoracic esophagectomy [11]. As cytokine concentrations vary substantially between patients, it is important to analyze both lungs of the same patient.

A variety of chemokines have recently been shown to play an important role in inflammation. One is the rat cytokine-induced neutrophil chemoattractant-1 (CINC-1). CINC-1 is an acute phase protein with the ability to recruit neutrophils [12]. The human equivalent to the rat CINC-1 is the growth-regulated peptide alpha GRO $\alpha$. To our knowledge, the role of GRO $\alpha$ as human equivalent to CINC-1 in the inflammatory reaction in patients undergoing thoracic surgery has not been studied so far.

Thus, the aim of this study was to analyze the inflammatory response represented by the pro-inflammatory cytokine IL-6, the anti-inflammatory cytokine interleukin-1 receptor antagonist (IL-1RA) and the chemokine GRO $\alpha$ in the operated, collapsed and the non-operated, ventilated lungs, in the pleural space and the peripheral blood in patients undergoing lobectomy for cancer with special interest in the reaction of the chemokine GRO $\alpha$. We hypothesized that the pro-inflammatory GRO $\alpha$ shows a similar reaction to the pro-inflammatory cytokine IL-6.

\section{Patients and methods}

From the $1^{\text {st }}$ of June 2007 all patients undergoing thoracotomy and resection for non-small cell lung cancer at the University Hospital Basel, Switzerland, were assessed for eligibility to be included in this prospective observational study. Exclusion criteria were pneumonectomy, minimal invasive procedures and refusal of the patient to participate. The Ethics committee of the state of Basel has approved the study. Informed consent was obtained from all patients.

\section{Anesthetic procedure and surgery}

Anesthetic procedures were standardized for all patients including the use of double-lumen endobronchial tubes under fiber-optic control to allow single lung ventilation. All patients received a thoracic epidural catheter with continuous infusion of local anesthetics both intraoperatively (ropivacaine $0.3 \%$ ) and postoperatively (bupivacaine $0.125 \%$ ). Total intravenous anesthesia was applied using bolus doses of fentanyl and continuous infusions of propofol and remifentanil intraoperatively and tempered until endotracheal extubation. Muscle relaxation (intraoperatively only) was achieved using bolus doses of rocuronium. One-lung ventilation during thoracotomy followed the principles of a lung protective strategy, using pressure-limited or pressure-controlled ventilation modes with tidal volumes of $<7 \mathrm{ml} / \mathrm{kg}$ body weight, positive end-expiratory pressure of 3-5 cm H2O and limiting peak inspiratory pressures to $<30 \mathrm{~cm} \mathrm{H} 2 \mathrm{O}$. Inspired oxygen concentration on the ventilated lung was set to $100 \%$ at the beginning and gradually reduced thereafter based on the arterial oxygen tension measured by repeated blood gas analyses [13-15]. Continuous monitoring included ECG analysis, measurement of arterial oxygen saturation with pulse oxymetry and invasive arterial as well as central venous pressure monitoring. Blood samples were drawn intermittently at predefined time points for blood gas and further laboratory parameter analysis.

Surgery was performed by two consultant thoracic surgeons with the following surgical technique: after performing a lateral thoracotomy with entering the pleural cavity either through the fourth or the fifth intercostal space the lobe with the tumor was mobilized by preparation of the hilum and the interlobar fissures. During this procedure a part of the systematic mediastinal lymph node dissection according to the American Thoracic Society mapping was performed [16]. Then the tumor was resected either by a lobectomy, a bilobectomy, a sleeve-lobectomy or by an anatomical segmentectomy using staplers for the vascular, bronchial and parenchymal resection. After completing the systematic lymph node dissection the operation was finished by positioning one or two chest tubes.

\section{BAL, pleural lavage and peripheral blood samples}

Bilateral BAL was performed in all patients in supine position after intubation and at the completion of surgery. The bronchoscope was wedged in the lower bronchus of both lungs and a lavage with $50 \mathrm{ml}$ of sterile saline was performed. The BAL fluid was immediately centrifuged at 2500rpm for 15 minutes and the supernatant stored at $-20^{\circ} \mathrm{C}$.

Lavage of the pleural space was performed after thoracotomy and before closure of the thoracotomy with $100 \mathrm{ml}$ of sterile saline. On day 1-3, pleural fluid samples were taken in a standardized way. The tubes were clamped close to the chest and the collection system. Then the pleural fluid was aspirated from the tube using a standard 20 gauge needle. All samples were taken by the same investigator. The fluid was processed as described above for the BAL samples. 
Peripheral venous blood samples were obtained at the same time as the BAL and pleural fluid samples on the day of surgery and on day 1-3. Again, the samples were processed as described.

\section{Cytokine assays}

The concentrations of IL-6, IL-1RA and GRO $\alpha$ in the BAL, pleural space and blood samples were determined with enzyme-linked immune-sorbent assays (ELISA, R \& D Systems, Minneapolis, MN, USA). To standardize the BAL fluid samples for optimal comparison, we extrapolated the results retrieved in the ELISA to a sample volume of $10 \mathrm{ml}$.

\section{Statistical analysis}

Comparison of data between the groups was undertaken using Chi-square tests for categorical data, and Wilcoxon signed rank tests for continuous data. Data is presented as mean values with standard deviation (SD) or median values with inter-quartile range (IQR) as appropriate. Based on a paired t-test with a type 1 error set at 0.05 the sample size of 15 patients allowed an $82 \%$ power to detect a size effect difference of 0.8 . Statistical significance was set at $\mathrm{p}<0.05$. Statistical analyses were performed with Medcalc $^{\circledR}$, Version 9 for Windows.

\section{Results}

\section{Patients, pathology and morbidity}

There were 7 men and 8 women in the study cohort. The mean age was 65 years (SD 13 years) and mean body mass index was $24.9 \mathrm{~kg} / \mathrm{m}^{2}$ (SD $5.8 \mathrm{~kg} / \mathrm{m}^{2}$ ). Preoperative pulmonary function tests showed a mean forced expiratory volume (FEV1) of 2.3 liters (SD 0.9 liters) and a vital capacity (VC) of 3.3 liters (SD 1.1 liters). The mean FEV1/VC percentage was $71.0 \%$ (SD 14.1.0\%). Mean cardiac ejection fraction determined by preoperative echocardiography was $56.5 \%$ (SD 7.0\%).

Chronic obstructive pulmonary disease was present in three patients $(20 \%)$, five patients had cardiac comorbidities (33\%, two with atrial fibrillation, three with coronary heart disease), and five patients (33\%) had pre-existing renal impairment. Table 1 summarizes the surgical, anesthetic and the pathological data. There were no deaths and no surgical morbidity. The only postoperative morbidity was two patients with pneumonia.

\section{BAL fluid cytokine assay}

The BAL cytokine and chemokine measurements showed substantial inter-individual differences in both the operated, collapsed and non-operated, ventilated lung for all mediators as demonstrated for IL-6 as example in Figures 1, 2 and 3 . The results of the BAL measurements are demonstrated in table 2. Except for IL-6, no differences between the operated, collapsed and non-operated, ventilated lung
Table 1 Surgical and pathological data

\begin{tabular}{ll}
\hline SURGICAL PROCEDURES & \\
LOBECTOMY & 11 \\
BI-LOBECTOMY & 1 \\
SEGMENTECTOMY & 1 \\
SLEEVE LOBECTOMY & 2 \\
\hline MEAN LENGTH OF OPERATION IN MINUTES (SD) & $190(59)$ \\
\hline MEAN LENGTH OF ANAESTHETIC PROCEDURE IN MINUTES & $402(91)$ \\
(SD) & \\
\hline MEAN LENGTH OF ONE LUNG VENTILATION IN MINUTES (SD) & $156(73)$ \\
\hline MEAN BLOOD LOSS IN MILILITRES (SD) & 420 \\
& $(156)$ \\
\hline TYPE OF TUMOR & 3 \\
LARGE CELL CARCINOMA & 9 \\
ADENOCARCINOMA & 3 \\
\hline SQUAMOUS CELL CANCER & 3 \\
\hline
\end{tabular}

occurred. Over time (at intubation vs. end of surgery) the pro-inflammatory IL-6 and the anti-inflammatory IL-1RA showed a significant increase in the operated, collapsed lung (IL-6 p $<0.001$, IL-1RA $\mathrm{p}<0.001$ ), whereas in the non-operated, ventilated lung only IL-6 significantly increased ( $p=0.006)$ but not IL-1RA ( $p=0.525)$. GRO $\alpha$ showed no significant change over time (operated, collapsed lung $\mathrm{p}=0.720$, non-operated, ventilated lung $\mathrm{p}=0.978)$.

\section{Blood and pleural fluid cytokine assays}

The pleural fluid and blood cytokine assays demonstrated less inter-individual differences as shown for IL-6 in Figure 4. IL-1RA demonstrated a similar interindividual pattern whereas GRO $\alpha$ did not. Table 3 shows the results of the pleural and blood cytokine and chemokine assays. The cytokines reacted significantly more pronounced in the pleural fluid compared to the blood, starting with a certain delay on the first postoperative day.

The pro-inflammatory IL-6 significantly increased early in the blood, already at the end of surgery, thus only a few hours after the surgical trauma (at intubation $4 \mathrm{pg} / \mathrm{ml}$, at end of surgery $38 \mathrm{pg} / \mathrm{ml} ; \mathrm{p}=0.001)$. From the end of surgery to day one, the concentrations increased further, however, not reaching statistical significance (at end of surgery $38 \mathrm{pg} / \mathrm{ml}$, day one $99 \mathrm{pg} / \mathrm{ml}$; $\mathrm{p}=0.153)$. Although the anti-inflammatory IL-1RA also increased, this increase was not significant. GRO $\alpha$ was not detectable in the blood.

In the pleural fluid, IL-6 levels increased on day one, but not at the end of surgery (at intubation $14 \mathrm{pg} / \mathrm{ml}$, at the end of surgery $417 \mathrm{pg} / \mathrm{ml}$; $\mathrm{p}=0.168$; day one 27309 $\mathrm{pg} / \mathrm{ml} ; \mathrm{p}<0.001)$. IL-1RA levels were significantly higher at the end of surgery compared to the baseline at the intubation, and increased more significantly on day 

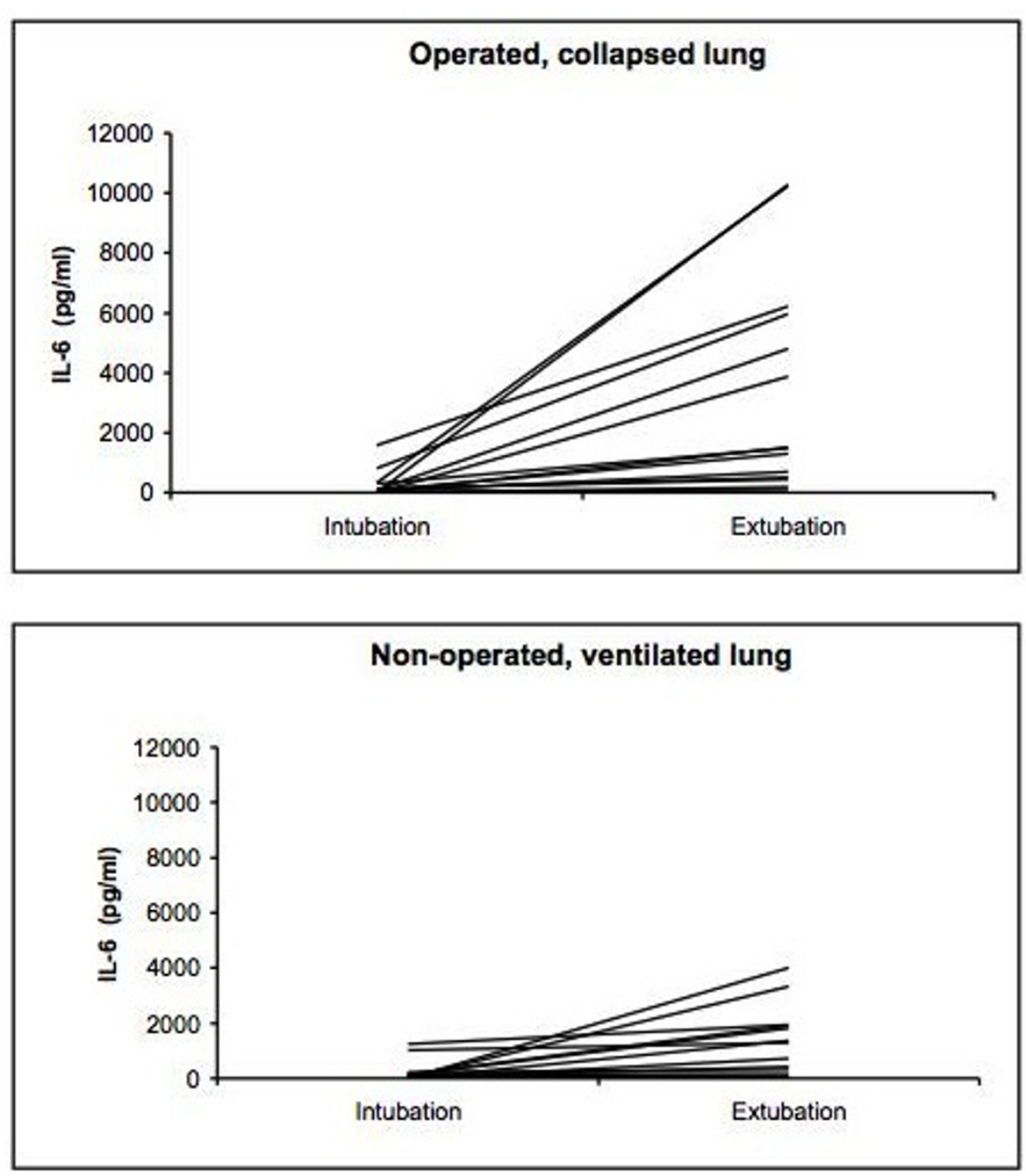

Figure 1 Course of IL- 6 in the operated collapsed and non-operated ventilated lungs in the individual 15 patients.

one (at intubation $46 \mathrm{pg} / \mathrm{ml}$, at the end of surgery 267 $\mathrm{pg} / \mathrm{ml} ; \mathrm{p}=0.034$; day one $20277 \mathrm{pg} / \mathrm{ml} ; \mathrm{p}<0.001)$. GRO $\alpha$ showed a similar pattern as IL-1RA (at intubation $17 \mathrm{pg} / \mathrm{ml}$, at the end of surgery $50 \mathrm{pg} / \mathrm{ml}$; $\mathrm{p}=$ 0.007; day one $258 \mathrm{pg} / \mathrm{ml} ; \mathrm{p}<0.001)$.

\section{Discussion}

The main finding of this study is the fact that the chemokine GRO $\alpha$ did not react similarly to the cytokines IL-6 and IL-1RA in the BAL and the blood. All patients showed a significant increase of the bronchoalveolar cytokines in both the operated, collapsed and non-operated, ventilated lungs. Analyzing BAL fluid from both lungs of the same patient is important to avoid bias due to the substantial variation in cytokine levels in the individual patient $[10,17]$. Our results support this finding as the inter-individual difference in both the operated, collapsed and the non-operated, ventilated lung, respectively, was substantial for all three mediators. To our knowledge, no study has analyzed the inflammatory response in both lungs of the same patient in open lung surgery. In most patients the increase of IL- 6 levels in the BAL fluid was moderate, but in some patients the IL-6 levels were very high, explaining the differences between the median and mean values. In contrast, in the pleural fluid and the blood the interpatient variability was less pronounced for IL-6 and IL-1RA, and no variability occurred for GRO $\alpha$. Some patients had a more pronounced reaction compared with the majority, both in the pleural fluid and in the blood. The reason for this remains unclear, as we did not detect any difference in the frequency of inflammatory complications between these patients. A number of studies reported an inter-subject variability of various inflammatory markers, but again the exact reasons remain unclear $[18,19]$. Aaron et al. analyzed sputum and serum specimens from patients with stable chronic obstructive 


\section{Operated, collapsed lung}
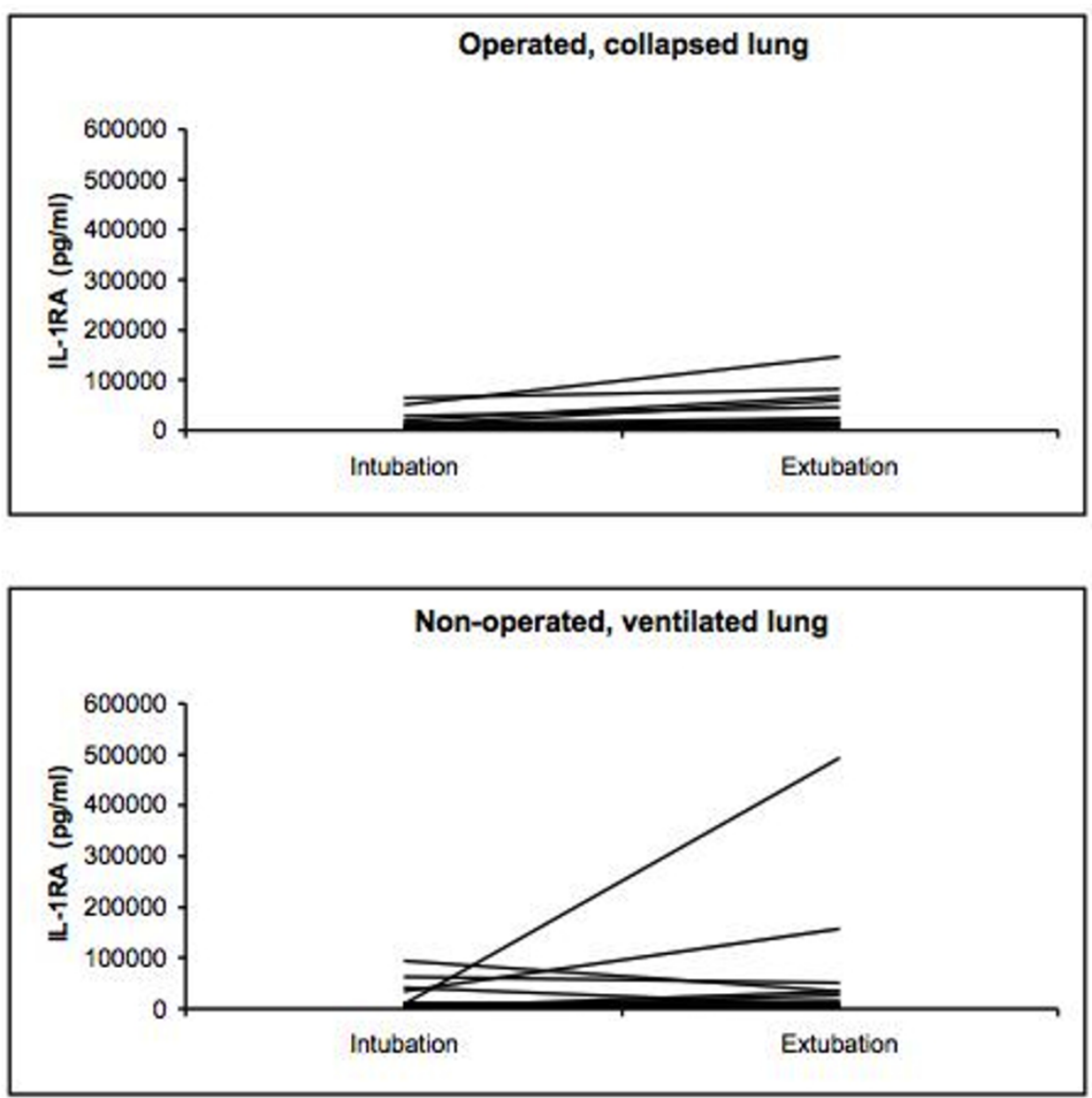

Figure 2 Course of IL-1RA in the operated collapsed and non-operated ventilated lungs in the individual 15 patients.
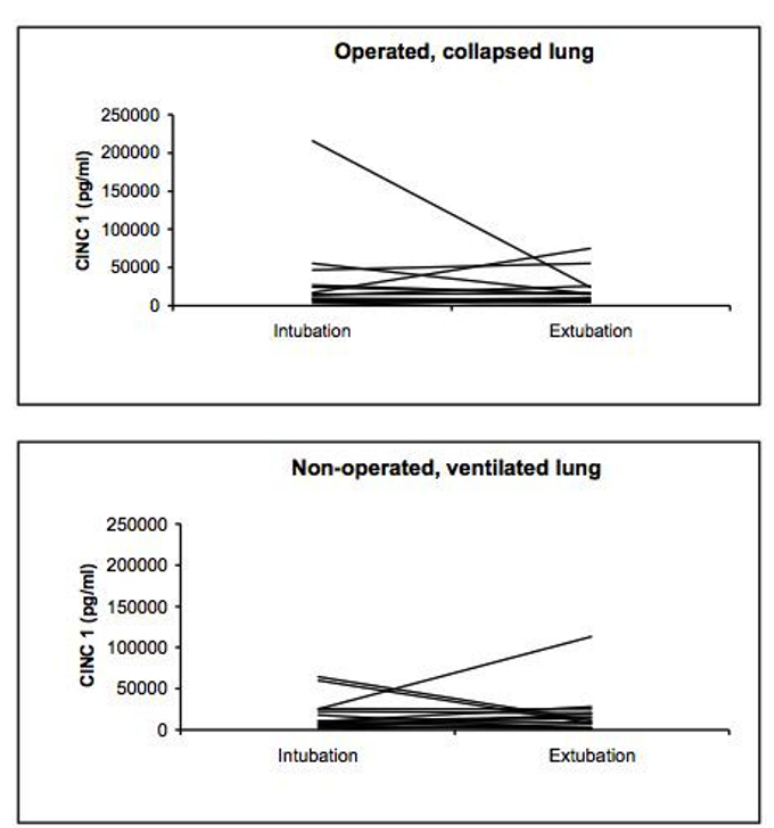

Figure 3 Course of CINC-1 in the operated collapsed and non-operated ventilated lungs in the individual 15 patients 
Table 2 Comparison of the median and mean cytokine levels in the BAL fluid of the right and left lung

BAL COLLAPSED RATIO OF CYTOKINE RESPONSE BAL VENTILATED RATIO OF CYTOKINE RESPONSE P VALUE\#

OPERATED LUNG COLLAPSED OPERATED LUNG* NON-OPERATED VENTILATED NON-OPERATED LUNG* BAL OPERATED COLLAPSED LUNG COMPARED

LUNG TO BAL NON-OPERATED VENTILATED LUNG

\begin{tabular}{|c|c|c|c|c|c|}
\hline \multicolumn{6}{|l|}{$\begin{array}{l}\text { IL-6 (PG/ML), } \\
\text { MEDIAN/MEAN } \\
\text { (IQR) }\end{array}$} \\
\hline $\begin{array}{l}\text { AT } \\
\text { INTUBATION }\end{array}$ & 63/236 (4-271) & 13.5 & 118/222 (12-148) & 5.2 & 1.000 \\
\hline $\begin{array}{l}\text { END OF } \\
\text { SURGERY }\end{array}$ & $\begin{array}{l}1486 / 3176(452- \\
5681)\end{array}$ & & 710/1159 (99-1899) & & 0.010 \\
\hline \multicolumn{6}{|l|}{$\begin{array}{l}\text { IL-1RA (PG/ML), } \\
\text { MEDIAN/MEAN } \\
\text { (IQR) }\end{array}$} \\
\hline $\begin{array}{l}\text { AT } \\
\text { INTUBATION }\end{array}$ & $\begin{array}{l}\text { 7144/15289 (3316- } \\
17921)\end{array}$ & 2.3 & $\begin{array}{l}\text { 7144/19863 (3469- } \\
\text { 29394) }\end{array}$ & 2.9 & 0.670 \\
\hline $\begin{array}{l}\text { END OF } \\
\text { SURGERY }\end{array}$ & $\begin{array}{l}14837 / 35242(9803- \\
56578)\end{array}$ & & $\begin{array}{l}12878 / 57543(5943- \\
35014)\end{array}$ & & 0.252 \\
\hline \multicolumn{6}{|l|}{$\begin{array}{l}\text { GRO } \alpha \text { (PG/ML), } \\
\text { MEDIAN/MEAN } \\
\text { (IQR) }\end{array}$} \\
\hline $\begin{array}{l}\text { AT } \\
\text { INTUBATION }\end{array}$ & $\begin{array}{l}13467 / 30597(6967- \\
26499)\end{array}$ & 0.6 & $\begin{array}{l}10137 / 18043(5132- \\
24379)\end{array}$ & 1.0 & 0.720 \\
\hline $\begin{array}{l}\text { END OF } \\
\text { SURGERY }\end{array}$ & $\begin{array}{l}\text { 15133/19187 (7330- } \\
22047)\end{array}$ & & $\begin{array}{l}11252 / 18552 \text { (3487- } \\
20038)\end{array}$ & & 0.599 \\
\hline
\end{tabular}

*Concentration at intubation as base line for calculation of ratio

\# Wilcoxon paired samples test 

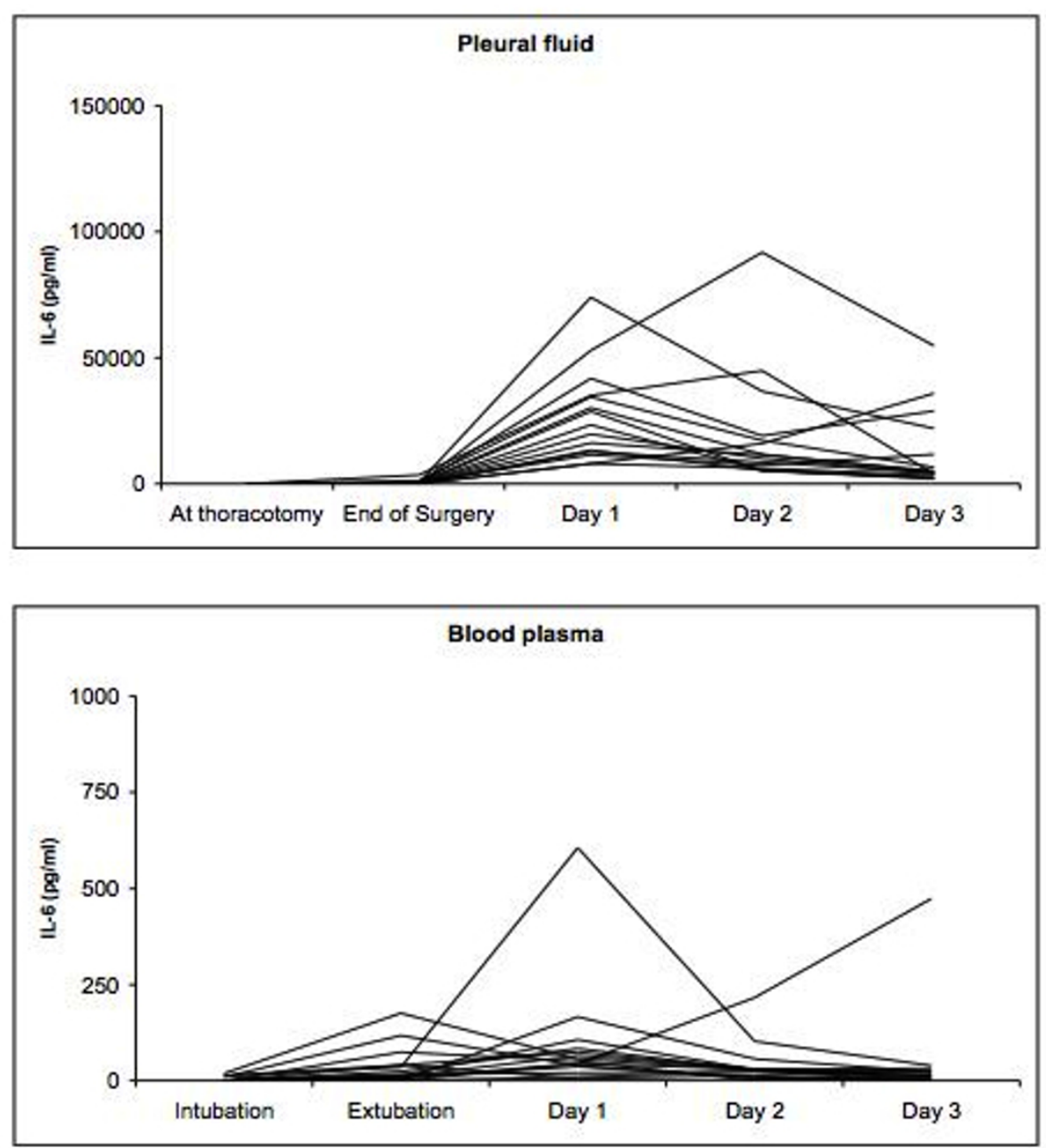

Figure 4 Course of IL- 6 in the pleural fluid and blood plasma in the individual 15 patients.

pulmonary disease and controls, and found similar results to our study, i.e. a more substantial reaction in the specimen sampled directly from the lungs [19]. These authors explained their finding with the higher variability in dayto-day amount and dilution of analyzed sputum, however, after correction of their results by normalizing for the sputum total protein some of the variability remained.

The pro-inflammatory IL- 6 reacted more on the operated, collapsed lung and showed in median a 13-time higher concentration in the BAL fluid at the end of surgery. The anti-inflammatory IL-1RA reacted in both lungs similarly, with a two- to three-fold increase. This is in contrast to a recent analysis of our group in patients who underwent transthoracic esophagectomy with OLV, where a more pronounced reaction on the ventilated side was observed [11]. One possible explanation for this difference is the fact that in lung surgery the tissue damage is created directly on the lung, thus triggering a more severe reaction on the operated side that is subsequently measured in the BAL fluid. In contrast, in esophagectomies the inflammatory response is likely to be triggered by the OLV itself through high oxygen concentrations and the direct mechanical stress on the alveolar walls [20].

GRO $\alpha$ showed no increase in the BAL fluid. GRO $\alpha$ is the human equivalent to the rat CINC-1 that is an acute phase protein and induces recruitment of neutrophils, thus is a pro-inflammatory mediator. We hypothesized that GRO $\alpha$ levels would increase similar to the proinflammatory cytokines, in both lungs. Only limited data on chemokines after surgical procedures exist. Seitz et al. showed that chemokine levels in BAL fluid of rats subjected to blunt chest trauma increased compared to sham [21]. Schilling et al. demonstrated an increase of intra-alveolar granulocytes in the ventilated lung in patients undergoing thoracic surgery with OLV [22]. In their study, the increase in cells occurred two hours postoperatively. One reason for the lack in increase of 
Table 3 Comparison of the median and mean cytokine levels in the pleura fluid with the levels in the peripheral blood

\begin{tabular}{|c|c|c|c|c|c|}
\hline & PLEURAL FLUID & $\begin{array}{l}\text { RATIO OF CYTOKINE RESPONSE } \\
\text { PLEURAL FLUID* }\end{array}$ & $\begin{array}{l}\text { PERIPHERAL } \\
\text { BLOOD }\end{array}$ & $\begin{array}{l}\text { RATIO OF CYTOKINE RESPONSE } \\
\text { PERIPHERAL BLOOD* }\end{array}$ & $\begin{array}{l}\text { P VALUE\# } \\
\text { PLEURAL FLUID VERSUS } \\
\text { BLOOD }\end{array}$ \\
\hline \multicolumn{6}{|l|}{$\begin{array}{l}\text { IL-6 (PG/ML), MEDIAN/MEAN } \\
(\text { (IQR) }\end{array}$} \\
\hline $\begin{array}{l}\text { AT THORACOTOMY/ } \\
\text { INTUBATION }\end{array}$ & 0/14 (0-21) & 29.8 & 0/4 (0-10) & 9.5 & 0.109 \\
\hline END OF SURGERY & $58 / 417(22-396)$ & 1950.6 & 16/38 (7-41) & 24.8 & 0.085 \\
\hline DAY 1 & $\begin{array}{l}23448 / 27309 \text { (12900- } \\
34929)\end{array}$ & 1889.9 & 54/99 (39-84) & 10.5 & $<0.001$ \\
\hline DAY 2 & $\begin{array}{l}11396 / 26458(6510- \\
18582)\end{array}$ & 914.3 & 28/42 (16-31) & 11.0 & $<0.001$ \\
\hline DAY 3 & $\begin{array}{l}4709 / 12800(3590- \\
19392)\end{array}$ & & $13 / 44(2-24)$ & & $<0.001$ \\
\hline \multicolumn{6}{|l|}{$\begin{array}{l}\text { IL-1RA (PG/ML), MEDIAN/ } \\
\text { MEAN (IQR) }\end{array}$} \\
\hline $\begin{array}{l}\text { AT THORACOTOMY/ } \\
\text { INTUBATION }\end{array}$ & $9 / 46(0-76)$ & 5.8 & 75/470 (0-979) & 1.2 & 0.102 \\
\hline END OF SURGERY & 140/267 (11-252) & 440.8 & 134/580 (0-913) & 1.6 & 0.525 \\
\hline DAY 1 & $\begin{array}{l}16239 / 20277(10210- \\
23527)\end{array}$ & 335.5 & $516 / 735(0-1251)$ & 1.1 & $<0.001$ \\
\hline DAY 2 & $\begin{array}{l}8062 / 15435(3477- \\
15589)\end{array}$ & 261.3 & 112/492 (4-949) & 1.1 & $<0.001$ \\
\hline DAY 3 & $\begin{array}{l}4364 / 12018(3152- \\
13764)\end{array}$ & & 147/524 (0-1184 & & $<0.001$ \\
\hline \multicolumn{6}{|l|}{$\begin{array}{l}\text { GRO } \alpha \text { (PG/ML), MEDIAN/ } \\
\text { MEAN (IQR) }\end{array}$} \\
\hline $\begin{array}{l}\text { AT THORACOTOMY/ } \\
\text { INTUBATION }\end{array}$ & $3 / 17(0-30)$ & 2.9 & 0/183 (0-257) & 1.1 & 0.193 \\
\hline END OF SURGERY & $25 / 50(7-57)$ & 15.2 & 0/201 (0-224) & 0.7 & 0.525 \\
\hline DAY 1 & 172/258 (118-306) & 11.2 & 0/136 (0-282) & 0.6 & 0.017 \\
\hline DAY 2 & 64/190 (25-179) & 7.4 & 0/114 (0-145) & 0.6 & 0.268 \\
\hline DAY 3 & $97 / 125$ (29-182) & & 0/105 (0-116) & & 0.389 \\
\hline
\end{tabular}

The pleural samples were taken immediately after the thoracotomy and before closure of the thoracotomy. On day 1-3 the pleural and peripheral blood samples were taken at the same time.

*Concentration at intubation as base line for calculation of ratio (means used for calculation)

\# Wilcoxon paired samples test 
GRO $\alpha$ levels in our study might be the time course of the chemokine in the lung. In our study, GRO $\alpha$ levels peaked in the pleural fluid on day one whereas no substantial increase was seen at the end of surgery. This might indicate a slower increase over time. The role of the various chemokines in inflammation is not clear, however, their potential role in targeting and blocking inflammatory processes has been recognized in hepatic diseases, rheumatoid arthritis or allergic asthma [23,24].

In the peripheral blood, the pro-inflammatory IL-6 levels increased substantially and peaked on day one. The antiinflammatory IL-1RA showed also an increase, but less pronounced. Similar findings have been described in most major surgical procedures. However, transthoracic procedures seem to trigger a more pronounced pro-inflammatory reaction [1]. The main reason seems to be the thoracotomy. Yim et al. demonstrated lower IL- 6 levels in video-assisted thoracic surgery (VATS) compared to open thoracic surgery [5]. For both, IL-6 and IL-1RA, the increase in the peripheral blood occurred already at the end of surgery, thus early in the time course and only shortly after the surgical trauma occurred. Also, both cytokines showed significantly higher levels in the locally sampled fluids, i.e. BAL and pleural fluid. The inflammatory reaction seems to be generated primarily locally. Also, depression of cytokine production in the peripheral blood might contribute to this less pronounced increase [25]. Considering the high postoperative morbidity of these operations, the early postoperative IL-6 levels could be of interest for early detection of infectious complications. IL- 6 has been detected as early marker for postoperative sepsis [26]. In our study, no analysis stratified according postoperative morbidity was possible due to a low number of patients and a very low postoperative complication rate.

Similar to the levels in the BAL fluid, we were not able to detect an increase in the GRO $\alpha$ levels in the blood. On postoperative day one, the GRO $\alpha$ level in the blood was even decreased. We were not able to explain this finding. Our results indicate that the usefulness of GRO $\alpha$ levels in the peripheral blood as markers of inflammation may be limited.

In the pleural fluid, IL-6, IL-1RA and GRO $\alpha$ increased. Similar to the blood, the peak occurred on day one, but the increase was already detectable at the end of the surgery. The levels in the pleural fluid were significantly higher compared to the blood. This finding is consistent to other reports measuring pleural fluid cytokine levels in patients undergoing esophagectomy $[27,28]$. Overall, data on the inflammatory reaction in the pleural space is scarce. Weissflog et al. demonstrated higher pleural concentrations of IL-10 and other cytokines in non-malignant diseases, and in patients undergoing VATS [29]. Szczesny et al. showed substantially higher levels of IL-6 and
IL-1RA in the pleural fluid compared to the serum [30]. The elevation of cytokines persists to day three, which may also be influenced by the thoracic drains. The pleural cavity seems to be an important location of inflammation. GRO $\alpha$ levels were only elevated in this compartment. GRO $\alpha$ is a potent chemoattractant for neutrophils, and this influx of cells might also influence the tumor-immunological environment. The production of oxygen radicals by neutrophils might decrease the ability of anti-tumor acting cells, such as natural killer cells, to eliminate free tumor cells.

The main limitation of this study is the number of patients, and thus, our results mandate careful interpretation. However, with our sample size of 15 patients we were powered up to detect a major difference between operated and non-operated lungs.

Performing BAL on both lungs of each patients is complex, time consuming and not without risk. The results presented in this study are, to our knowledge, the first demonstrating the time course of chemokines in lung surgery and give a first insight in the cytokine and chemokine reaction in complex thoracic surgery. Further studies to determine the impact of the locoregional inflammatory response and its clinical relevance after thoracic surgery are necessary.

\section{Conclusion}

The inflammatory response of pro- and anti-inflammatory cytokines affects both the collapsed operated and the ventilated contralateral lungs. The inter-individual difference was present in the BAL of the lungs but less in the pleural space and in the blood, respectively. The difference in extent of response underlines the complexity of the inflammatory processes that arise during OLV in thoracic surgery. Loco-regional inflammatory reactions were more pronounced compared to the blood. The inflammatory response occurred shortly after the surgical trauma, thus indicating that measurements must be done timely. GRO $\alpha$ increased in the pleural fluid but neither in the BAL fluid nor in the blood and might not be useful as marker for systemic inflammatory response in complex surgery.

\section{List of abbreviations}

OLV: One-lung ventilation; BAL: Broncho-alveolar lavage; IL: Interleukin, GROa: Growth-regulated peptide alpha; CINC-1: Cytokine-induced neutrophil chemoattractant-1; IL-1RA: Interleukin-1 receptor antagonist; ELISA: Enzymelinked immune-sorbent assay; ARDS: Adult respiratory distress syndrome; SD: Standard deviation; IQR: Inter-quartile range; FEV1: forced expiratory volume; VC: Vital capacity; VATS: Video-assisted thoracic surgery

\section{Acknowledgements}

The authors thank Ms. L. Reyes for her skillful laboratory work in performing the ELISA's. The authors also thank Professor Adrian Esterman, PhD, for his help with the statistical analysis. 


\section{Author details}

'Department of Surgery, University Hospital Basel, Switzerland. ${ }^{2}$ Thoracic Surgery, University Hospital Basel, Switzerland. ${ }^{3}$ Institute of Anaesthesiology, University Hospital Zürich, Switzerland. ${ }^{4}$ Pulmonary Medicine, University Hospital Basel, Switzerland.

\section{Authors' contributions}

$A B$ sampled the fluids, performed the laboratory work and was involved in drafting the manuscript; FG performed the pleural lavages and the surgery, was involved in processing the samples and drafting the manuscript; BBS participated in the design of the study, performed the laboratory work and reviewed the draft; MT performed the BAL, was involved in processing the samples and critically reviewed the manuscript; DL performed the pleural lavages and the surgery, was involved in the statistical analysis and the drafting of the manuscript; DO was involved in the design of the study and the drafting of the manuscript and critically reviewed the paper; UZ designed the study, drafted the manuscript, performed the statistical analysis and critically reviewed the paper. All authors read and approved the final manuscript.

\section{Competing interests}

The authors declare that they have no competing interests.

Received: 13 May 2011 Accepted: 11 November 2011

Published: 11 November 2011

\section{References}

1. Sakamoto K, Arakawa H, Mita S, Ishiko T, Ikei S, Egami H, Hisano S, Ogawa M: Elevation of circulating interleukin 6 after surgery: factors influencing the serum levels. Cytokine 1994, 6:181-186.

2. Baudouin SV: Lung injury after thoracotomy. Br J Anaesth 2003, 91:132-142.

3. Jordan S, Mitchell JA, Quinlan GJ, Goldstraw P, Evans TW: The pathogenesis of lung injury following pulmonary resection. Eur Respir I 2000, 15:790-799.

4. Halbertsma FJ, Vanecker M, Scheffel GJ, van der Hoeven JG: Cytokines and biotrauma in ventilator-induced lung injury: a critical reviw of the literature. Neth J Med 2005, 63:382-392.

5. Yim AP, Wan S, Lee TW, Arifi AA: VATS lobectomy reduces cytokine responses compared with conventional surgery. Ann Thorac Surg 2000, 70:243-247.

6. Atwell DM, Grichnik KP, Newman MF, Reves JG, McBride WT: Balance of proinflammatory and anti-inflammatory cytokines at thoracic cancer operation. Ann Thorac Surg 1998, 66:1145-1150.

7. Nagahiro I, Andou A, Aoe M, Sano Y, Date H, Shimizu N: Pulmonary function, postoperative pain, and serum cytokine level after lobectomy: A comparison of VATS and conventional procedure. Ann Thorac Surg 2001, 72:362-365.

8. Takenaka K, Ogaa E, Wada H, Hirata T: Systemic inflammatory response syndrome and surgical stress in thoracic surgery. J Crit Care 2006, 21:48-55.

9. Yamada T, Hisanaga M, Nakajima Y, Kanehiro H, Watanabe A, Ohyama T, Nishio K, Sho M, Nagao M, Harada A, Matsushima K, Nakano H: Serum interleukin-6, interleukin-8, hepatocyte growth factor, and nitric oxide changes during thoracic surgery. World J Surg 1998, 22:783-790.

10. Cree RTJ, Warnell I, Staunton M, Shaw I, Bullock R, Griffin SM, Baudouin SV: Alveolar and plasma concentrations of interleukin-8 and vascular endothelial growth factor following oesophagectomy. Anaesthesia 2004, 59:867-871.

11. Zingg U, Forberger J, Frey DM, Esterman AJ, Oertli D, Beck-Schimmer B, Zollinger A: Inflammatory response in ventilated left and collapsed right lungs, serum and pleural fluid, in transthoracic esophagectomy for cancer. Eur Cytokine Netw 2010, 21:50-57.

12. Soares DM, Machado RR, Yamashiro LH, Melo MC, Souza GE: Cytokineinduced neutrophil chemoattractant (CINC)-1 induces fever by a prostaglandin-dependent mechanism in rats. Brain Research 2008, 1233:79-88.

13. Karzai $W$, Schwarzkopf $K$ : Hypoxemia during one-lung ventilation: prediction, prevention, and treatment. Anesthesiology 2009, 110:1402-1411.

14. De Conno E, Steurer MP, Wittlinger M, Zalunardo MP, Weder W, Schneiter D, Schimmer RC, Klaghofer R, Neff TA, Schmid ER, Spahn DR,
Z'graggen BR, Urner M, Beck-Schimmer B: Anesthetic-induced improvement of the inflammatory response to one-lung ventilation. Anesthesiology 2009, 110:1316-1326.

15. Aschkenasy SV, Hofer CK, Zalunardo MP, Zaugg M, Weder W, Seifert B, Pasch T, Zollinger A: Patterns of changes in arterial PO2 during one-lung ventilation: a comparison between patients with severe pulmonary emphysema and patients with preserved lung function. $J$ Cardiothorac Vasc Anesth 2005, 19:479-484.

16. Mountain CF, Dresler CM: Regional lymph node classification for lung cancer staging. Chest 1997, 111:1718-23.

17. Donnelly SC, Strieter RM, Kunkel SL, Walz A, Robertson CR, Carter DC, Grant IS, Pollok AJ, Haslett C: Interleukin-8 and development of adult respiratory distress syndrome in at-risk patient groups. Lancet 1993, 341:643-647.

18. Sapey E, Bayley D, Ahmad A, Newbold P, Snell N, Stockley R: Interrelationships between inflammatory markers in patients with stable COPD with bronchitis: intra-patient and inter-patient variability. Thorax 2008, 63:493-503.

19. Aaron SD, Vandemheen KL, Ramsay T, Zhang C, Avnur Z, Nikolcheva T, Quinn A: Multi analyte profiling and variability of inflammatory markers in blood and induced sputum in patients with stable COPD. Respir Res 2010, 11:41.

20. Dos Santos CC, Slutsky AS: Invited review: mechanisms of ventilatorinduced lung injury: a persepective. J Appl Physiol 2000, 89:1645-55.

21. Seitz DH, Niesler U, Palmer A, Sulger M, Braumüller ST, Perl M, Gebhard F, Knöferl MW: Blunt chest trauma induces mediator-dependent monocyte migration to the lung. Crit Care Med 2010, 38:1852-9.

22. Schilling T, Kozian A, Kretzschmar M, Huth C, Welte T, Buhling F, Hedenstierna G, Hachenberg T: Effects of propofol and desflurane anaesthesia on the alveolar inflammatory response to one-lung ventilation. Br J Anaesth 2007, 99:368-375.

23. Pease JE, Williams TJ: The attraction of chemokines as a target for specific anti-inflammatory therapy. Br J Pharmacol 2006, 147:S212-S221.

24. Ajuebor MN, Swain MG, Perretti M: Chemokines as novel therapeutic targets in inflammatory diseases. Biochem Pharmacol 2002, 63:1191-1196.

25. van Sandick JW, Gisbertz SS, ten Berge IJ, Moermeester MA, van der Pouw Kraan TC, Out TA, Obertop H, van Lanschot JJ: Immune response and prediction of major infection in patients undergoing transhiatal or transthoracic esophagectomy for cancer. Ann Surg 2003, 237:35-43.

26. Mokard D, Merlin M, Sannini A, Brun JP, Delpero JR, Houvenaeghel G, Moutardier V, Blache JL: Procalcitonin, interleukin 6 and systemic inflammatory response syndrome: early markers of postoperative sepsis after major surgery. Br J Anaesth 2005, 94:767-773.

27. Morita M, Yoshida R, Ikeda K, Egashira A, Oki E, Sadanaga N, Kakeji Y, Ichiki Y, Sugio K: Acute lung injury following an esophagectomy for esophageal cancer, with special reference to the clinical factors and cytokine levels of peripheral blood and pleural drainage fluid. Dis Esophagus 2008, 21:30-36.

28. Hisano S, Sakamoto K, Ishiko T, Kamohara H, Ogawa M: IL-6 and soluble IL6 receptor levels change differently after surgery both in the blood and the operative field. Cytokine 1997, 9:447-452.

29. Weissflog D, Kroegel C, Luttmann W, Grahmann PR, Hasse J: Leukocyte infiltration and secretion of cytokines in pleural drainage fluid after thoracic surgery. Chest 1999, 115:1604-1610.

30. Szczesny TJ, Slotwinski R, Stankiewicz A, Szczygiel B, Zaleska M, Kopacz M: Interleukin 6 and interleukin 1 receptor antagonist as early markers of complications after lung cancer surgery. Eur J Cardiothorac Surg 2007, 31:719-724.

doi:10.1186/1476-9255-8-32

Cite this article as: Breunig et al:: Cytokine \& chemokine response in the lungs, pleural fluid and serum in thoracic surgery using one-lung ventilation. Journal of Inflammation 2011 8:32. 